This item was submitted to Loughborough's Research Repository by the author.

Items in Figshare are protected by copyright, with all rights reserved, unless otherwise indicated.

\title{
The role of biopreservation in cell and gene therapy bioprocessing
}

\section{PLEASE CITE THE PUBLISHED VERSION}

http://dx.doi.org/10.18609/cgti.2017.037

\section{PUBLISHER}

Bioinsights

\section{VERSION}

AM (Accepted Manuscript)

\section{PUBLISHER STATEMENT}

This work is made available according to the conditions of the Creative Commons Attribution-NonCommercialNoDerivatives 4.0 International (CC BY-NC-ND 4.0) licence. Full details of this licence are available at: https://creativecommons.org/licenses/by-nc-nd/4.0/

\section{LICENCE}

CC BY-NC-ND 4.0

\section{REPOSITORY RECORD}

Rafiq, Qasim A., Alvin W. Nienow, Christopher J. Hewitt, and Karen Coopman. 2017. "The Role of Biopreservation in Cell and Gene Therapy Bioprocessing". figshare. https://hdl.handle.net/2134/25735. 


\title{
The role of biopreservation in cell and gene therapy bioprocessing
}

\author{
Qasim A. Rafiq ${ }^{1,2}$, Alvin W. Nienow ${ }^{3}$, Christopher J. Hewitt ${ }^{2}$, Karen \\ Coopman $^{4}$
}

${ }^{1}$ Advanced Centre for Biochemical Engineering, Department of Biochemical Engineering, University College London, London, WC1E 6BT, United Kingdom

${ }^{2}$ Aston Medical Research Institute, School of Life and Health Sciences, Aston University, Birmingham, B4 7ET, United Kingdom

${ }^{3}$ School of Chemical Engineering, University of Birmingham, Edgbaston, Birmingham, B15

2TT United Kingdom

${ }^{4}$ Centre for Biological Engineering, Loughborough University, Leicestershire, LE11 3TU, United Kingdom

Correspondence: Dr Qasim Rafiq, Advanced Centre for Biochemical Engineering, Department of Biochemical Engineering, University College London, Gower Street, London, WC1E 6BT, United Kingdom

E-mail: q.rafiq@ucl.ac.uk 


\section{Introduction}

Cell and gene-based therapies (CGTs) represent a novel therapeutic modality that have the potential to address the significant medical challenges associated with chronic, age-related clinical indications and provide a treatment option for a range of unmet medical needs. There are, however, numerous processing and manufacturing challenges that must be addressed before such therapies are considered commercially and clinically viable. A significant challenge associated with the manufacture of such therapies is ensuring cell quality and that the product's critical quality attributes (CQAs) [1] are retained throughout the entire bioprocess, from initial cell isolation through to delivery and administration to a patient. Unlike traditional biopharmaceutical manufacture, manufacturing paradigms for CGTs may involve an autologous (patient-specific), allogeneic (universal donor) or haplobank approach.

An important aspect of all CGT bioprocessing is biopreservation. This enables the creation of cell banks (master and working cell banks for allogeneic product manufacture or storage banks for patient specific material such as cord blood). This can uncouple the expansion and/or manipulation of cells from the clinic, creating product shelf-life and facilitates the transport/storage of any product intermediates (e.g. newly isolated cells or even viral vectors) too [2] Fig 1. Indeed, where the process necessitates transfer of cellular material from the clinic to an off-site facility for processing and/or expansion, biopreservation measures will be critical to product quality and success. This places particular emphasis on the appropriate selection of biopreservation methods, with a need to demonstrate that they do not adversely impact the product's CQAs. Moreover, the biopreservation methodology needs to align with the business and distribution model to ensure commercial success and should occur during early stages of development given the integral role biopreservation plays in the logistical and manufacturing bioprocessing considerations [3]. Biopreservation also determines the level of at-clinic processing, e.g. will the cells need to be thawed prior to administration or are they preserved and subsequently delivered at ambient temperature. Thus, in many CGT processes, it is likely that biological material will require at least one biopreservation step, if not more (Figure 1). This will exacerbated for gene therapy products where other biological material (e.g. viral vectors) are also likely to undergo an independent preservation process prior to their addition to the cellular material. 


\section{Types of biopreservation}

Biopreservation is often used synonymously with cryopreservation. However, whilst reviewing regulatory submissions for mesenchymal stem cell therapies to the FDA in 2012 reveals that freezing is certainly a key biopreservation method, with more than $80 \%$ of submissions involving a frozen product [4]. It is not the only biopreservation method that is being considered for commercial and clinical use. Indeed, given the need to retain the product CQAs and that multiple different manufacturing/distribution models are likely to be employed for CGTs (e.g. autologous, allogeneic and haplobank), it has become increasingly important to consider other types of biopreservation for the storage and transportation of biological material. This includes hypothermic preservation (i.e. 'cell pausing') at either ambient [5-7] or refrigerated chilled temperatures [8,9]. Ultimately, the decision as to which biopreservation method is most appropriate will need to take into account which method has the least effect on the product's CQAs whilst remaining both commercially, clinically and logistically viable.

\subsection{Cryopreservation}

Freezing is the most common biopreservation method employed in CGT processes [2], with the first successful cryopreservation taking place in 1949 with spermatozoa in glycerol [10]. Standard cryopreservation practise of cellular material usually involves a two-step controlled rate freezing (CRF) process: (1) the controlled reduction of the temperature of the cellular material to $-80^{\circ} \mathrm{C}$ at a rate of $1{ }^{\circ} \mathrm{C} / \mathrm{min}$, followed by, (2) reducing the temperature even further to $\leq-150^{\circ} \mathrm{C}$ usually by placing into liquid nitrogen, its vapour phase for long-term storage. This method of CRF has been demonstrated for both millilitre cryovials and in bags of large volumes $(>100 \mathrm{~mL})$ for both adult stem cells [11] and other mammalian cells [12, 13]. It has also been successfully employed for the human fibroblast-derived dermal substitute Dermagraft (Advanced Biohealing, USA) [14] in addition to the hMSC product, Prochymal, which has received conditional approval in New Zealand and Canada, and is available in the United States under an Expanded Access Programme for treatment of acute GVHD in children $[15,16]$. In the Health Canada summary basis of decision (SBD), Prochymal's shelf-life is identified as 2 years at $\leq-135^{\circ} \mathrm{C}[16]$. 
Cryopreservation usually enables high cell recovery, with $>90 \%$ cell viability immediately post-thaw. However, this is cell and process-dependent and delayed onset apoptosis can be caused [17] which is not detected immediately post-thaw by assays such as trypan blue exclusion. Indeed, there have been studies which, for example, have demonstrated that human embryonic stem cells are sensitive to cryopreservation with a relatively low recovery postthaw, in addition to changes in cell phenotype resulting in poor outcomes for cell functionality $[18,19]$. Moreover, whilst some studies have demonstrated an adverse effect on hMSC functionality with respect to T-cell suppression, response to IFN- $\gamma$, lower production of anti-inflammatory mediators and impaired blood regulatory properties immediately postthaw for hMSCs compared with actively proliferating hMSCs [20, 21], yet others have demonstrated that cryopreservation does not adversely affect the viability, immunomodulatory properties or differentiation capacity [22]. For example, Cruz et al. (2015) reported equivalency between cryopreserved and non-cryopreserved hMSCs [23]. François et al. (2012), one of the groups who reported that hMSCs were adversely impacted by cryopreservation did note that thawed hMSCs recovered their immunomodulatory functionality 24 hours post-culture [20] suggesting that a cell-recovery process may need to be incorporated post-thaw to retain viability and, more importantly, ensure functionality of the cryopreserved cells. If indeed this is necessary for the product to retain its CQAs, this increases process complexity and costs, with a particular consideration as to where the cellrecovery process step is conducted. Moreover, the differences between the aforementioned studies could also potentially be explained by differences in the cell handling, cryopreservation medium formulations, freezing protocols and thawing procedures. That the thawing process is often badly, if at all, controlled and that this may be responsible for some of the damage perceived to be caused by cryopreservation is now starting to be recognised by the community. For example, at ISCT 2017, one report highlighted the interplay between cooling rate and thawing rate for $\mathrm{T}$ cell recovery post-thaw [24]. To address this, rapid and specialised thawing devices are being developed such as the ThawSTAR from Medcision and VIA Thaw by Asymptote

As well as CRF, vitrification can also be used to cryopreserve cells. This involves the rapid cooling of the cellular material, thereby avoiding formation of both extra- and intracellular ice crystals [25] and generating amorphous ice. although vitrification has been employed successfully for multiple cell types, in particular, colonies of human embryonic stem cells (hESCs), where vitrification has resulted in high levels of viability and retention of 
functionality post-thaw [26-28]. However, this method uses significantly higher levels of cryoprotective agent (CPA) than in CRF to prevent ice crystallisation, and enable vitrification at a higher glass transition temperature and an achievable cooling rate. Also, although efforts are ongoing to generate larger scale vitrification methods, the high cooling rates needed mean that only small volumes (typically 1-20ul) may be vitrified at once [3], making this an unattractive option for freezing of cell therapies currently.

\subsubsection{Cryopreservation challenges}

Although cryopreservation is currently considered to be the industry standard for CGT biopreservation, there are numerous challenges and considerations. Primarily, it is critical to understand the implications of cryopreservation on the product's CQAs. This requires indepth understanding about the product's biological attributes, mechanism of action and safety profile. There are also concerns with the use of liquid nitrogen in a GMP environment, where it may compromise clean room air quality given the potential for contamination with microorganisms, particulates and debris during transport and storage [29-31]. To use liquid nitrogen in a clean GMP facility would require the use of validated sterilisation and/or filtration methods [31, 32]. This can, however, be overcome by omitting the use of liquid nitrogen and using an electrically-powered Stirling cryocooler which has been used for multiple human cell types including hESCs and alginate-encapsulated liver cells [31].

The most significant concern with cryopreservation is the use of CPAs, in particular the intracellular CPA, dimethyl sulphoxide (DMSO). DMSO, the most commonly used CPA, is classified by the FDA as a class 3 solvent [33] and is considered to be toxic to both cells and patients at room temperature . It is recommended that patients do not receive more than $1 \mathrm{~g} / \mathrm{kg}$ body weight/day of DMSO, with a maximum permissible limit of $50 \mathrm{mg} /$ day [34, 35]. Such concerns and restrictions have been put in place due to the toxicology issues associated with DMSO [36]. This concern is exacerbated with vitrification given the need to significantly increase the CPA concentrations to avoid ice crystal formation. Although DMSO is still the most commonly used CPA, alternatives are being considered for the cryopreservation of mammalian cells which pose a lower toxicity risk including trehalose [37] and sucrose [38]. These CPAs provide a similar level of protection to cellular material during freezing, however the challenge with these CPAs is their inability to penetrate the cell. The delivery of 
these CPAs into mammalian cells requires an additional process step such as electroporation or permeabilisation [37, 39, 40].

\subsection{Hypothermic storage}

Whilst it is generally recognised and accepted that for long-term storage (months/years), cryopreservation remains the most cost-effective and scientifically robust method, there are genuine concerns about the use of cryopreservation for short-term storage and transport due to the potential for ice crystal formation and potentially toxic CPA concentrations. A potential alternative biopreservation method which is amenable for short-term requirements (e.g. days) is hypothermic storage. This includes chilled preservation, a process where the temperature is reduced to $2-8^{\circ} \mathrm{C}$ and ambient preservation (e.g. room temperature). Refrigerated preservation is currently used for the transfusion of red blood cells (RBCs) for the treatment of severe anaemia. RBCs can be stored at refrigeration temperature for up to 42 days within an additive solution, where they can then be transported to the site of administration upon request [41]. Moreover, refrigeration temperatures have also been used for the storage and transportation or whole organs prior to transplantation [42, 43].

Much of the research and development activity for chilled preservation relates to storage and transportation of whole organs and red blood cells. However, with the increasing promise of CGTs, there has been renewed interest in short-term chilled preservation for CGT cell candidates, in particular stem cells. The commercial hypothermic preservation medium solution HypoThermosol Free Radical Solution (BioLife Solutions, USA) has been used for the successful storage and preservation of a range of cell types including hMSCs [44] and differentiated human neural stem cells (hNSCs) [45]. In the case of hMSCs, the cells retained $>85 \%$ viability after $96 \mathrm{~h}$ when stored at $4^{\circ} \mathrm{C}$ [44], and for the differentiated hNSCs, the cells were seeded onto cellular collagen constructs and placed into a range of different medium compositions for storage at $4^{\circ} \mathrm{C}$ for $48 \mathrm{~h}$. The cells which were preserved in the HTS-FRS medium composition demonstrated the least cell death $(<10 \%)$, even lower than cells which were preserved using DMSO under cryogenic conditions [45]. Indeed, recently, HTS was used for TiGenix's phase 1 clinical trial study where expanded allogeneic adipose-derived stem cells stored in HTS were administered to patients [46]. 
Although chilled preservation will not be used as a long-term biopreservation method, it has demonstrated significant potential for its ability to suitably preserve cells at refrigerated temperatures for time periods accounting for transportation across countries. Transporting a CGT product between countries a significant distance apart can take up to $24 \mathrm{~h}$, however this does not take into account transportation delays, customs checks and potential clinical complications. As such, the longer the cells can be shown to demonstrate the retention of their CQAs in the biopreservation formulation, the more flexibility this provides to the overall process [3]. The additional advantage of this type of preservation in comparison to cryopreservation is that much of the clinical infrastructure, logistics and supply chain aspects to enable chilled storage and transportation is already in place. As such, significant changes to current practice and facilities will unlikely be required.

Ambient temperature preservation simplifies the process even further compared to chilled preservation and does not require any additional infrastructure to maintain refrigerated or cryogenic temperatures, thereby reducing cost and process complexity. Unlike cryopreservation and, to a lesser extent, chilled preservation, the research with ambient temperature preservation is not as extensive and has only become an area of interest in light of the potential advantages this preservation method confers over the aforementioned preservation techniques. The potential of this technique is demonstrated by Chen et al. (2013) who demonstrated that they were able to store hMSCs and mouse ESCs (mESCs) inside alginate hydrogels for 5 days in ambient conditions in an air-tight environment. Cell viability post-preservation was found to be $80 \%$ and $74 \%$ for the hMSCs and mESCs respectively [47]. Similarly, Swioklo et al (2016) showed human adipose-derived stem cells could be encapsulated and stored at a range of temperatures, from 4-23C, although 15C was found to be the optimal [48]. The disadvantage to this method however is the need for a cell retrieval step which increases process complexity and will likely need to be undertaken at- or nearclinic. Ambient temperature cell preservation has also been reported for hair follicles which demonstrated adequate graft recovery post-preservation [49]. Additionally, Hunt et al. (2005) have reported the successful preservation of other mammalian cell types (CHO and HEK293 cells) at temperatures ranging between $6-24^{\circ} \mathrm{C}$ for $>3$ days [6]. 
As with chilled preservation, ambient temperature preservation is a potential technique that can be used for pooling of cells during the process (for example post-harvest from culture devices awaiting downstream processing), or indeed, used for storage and transportation to site of clinical administration. However, it is critical that the acceptable temperature ranges and timeframes are identified and validated, with the validated conditions making allowances for potential processing and/or transport delays. There should also be consideration of effect of multiple preservation steps (if employed) during a process and the cumulative effect of ambient temperature preservation throughout the process. Greater product and process understanding will facilitate the consideration of multiple processing options and increase overall process flexibility.

\subsubsection{Hypothermic preservation challenges}

There are two key challenges for chilled preservation. The first has been alluded to previously and relates to the maximum time period it can be effectively used, and importantly, validated as a biopreservation method. Although there has been promising research data that suggests chilled preservation in conjunction with specifically designed hypothermic medium preservation solutions can retain cell viability and functionality across multiple days, there is a greater burden of evidence required for validation.

The other key challenge with chilled preservation, and exacerbated for ambient preservation (discussed later), is the fact that chilled preservation only slows and does not arrest cellular functions, activity and metabolism. This results in the potential build-up of deleterious metabolites and, perhaps more critically, the depletion of important substrates required for cell maintenance [50, 51]. It should also be noted that although chilled preservation does not result in cellular damage arising from ice crystal formation or suffer from CPA toxicity issues experienced with cryopreservation, there are concerns about chilled preservation resulting in cold-induced cell damage [52]. This risk of cell damage is intrinsically linked to the preservation time, with a greater risk of cell damage and decreased viability with longer preservation times [3]. There are also concerns with chilled preservation that once rewarmed to the appropriate administration temperature, the increased production of free radicals and other deleterious metabolites may result in delayed onset cell death, which may not be noticeable immediately but potentially take hours or days to become apparent [53]. 
A key challenge with ambient temperature preservation is demonstrating the utility and efficacy of such a preservation at industrial scales and practical terms. Given the relative infancy of this area of research, it is expected further studies will be conducted outlining the promise and potential of this technique. At present however, there is little that has been conducted with relevant cell types with a focus on CGT manufacture and bioprocessing to be able to make a strong scientific case for ambient temperature preservation. However, should it be scientifically feasible, the advantages of ambient temperature preservation are substantial and would significantly reduce process, storage and transportation costs.

\section{Translational insight}

Biopreservation of biological material for CGTs is often considered too late in process development or not given its due attention because of what is often perceived as other, 'more important' development activities. However, for effective CGT process development, translational research activity with respect to biopreservation given its pivotal role in process development, storage, transportation and overall business model. It is critical to identify early in process development which biopreservation technique(s) (cryo-, chilled, or ambient preservation) is the most appropriate for the CGT. Cryopreservation will remain the only feasible biopreservation technique for long-term storage (months/years), however, both chilled and ambient preservation methods provide additional process flexibility, particularly with respect to interprocess pooling/storage and transportation across manufacturing and clinical facilities. As with any CGT process, it is unlikely that a universal biopreservation approach will be appropriate in all cases and ultimately needs to be determined after thorough development activity identifying effects of biopreservation on the product's CQAs and the implications of the biopreservation technique on the distribution and commercial models. 


\section{References}

1. Brandenberger, R., et al., Cell therapy bioprocessing. Bioprocess International, 2011. 9: p. 3037.

2. Coopman, K. and N. Medcalf, From production to patient: challenges and approaches for delivering cell therapies, in StemBook, The Stem Cell Research Community, Editor. 2014: doi/10.3824/stembook.1.97.1.

3. Jesson, H.E., et al., Storage and Delivery of Stem Cells for Cellular Therapies, in Stem Cell Manufacturing, J.M.S. Cabral, et al., Editors. 2016, Elsevier: Boston. p. 233-264.

4. Mendicino, M., et al., MSC-based product characterization for clinical trials: an FDA perspective. Cell Stem Cell, 2014. 14(2): p. 141-5.

5. Robinson, N.J., A. Picken, and K. Coopman, Low temperature cell pausing: an alternative short-term preservation method for use in cell therapies including stem cell applications. Biotechnol Lett, 2014. 36(2): p. 201-9.

6. Hunt, L., et al., Low-temperature pausing of cultivated mammalian cells. Biotechnol Bioeng, 2005. 89(2): p. 157-63.

7. Eidet, J.R., et al., The impact of storage temperature on the morphology, viability, cell number and metabolism of cultured human conjunctival epithelium. Curr Eye Res, 2015. 40(1): p. 30-9.

8. Matsumoto, N., et al., Successful liquid storage of peripheral blood stem cells at subzero nonfreezing temperature. Bone Marrow Transplant, 2002. 30(11): p. 777-84.

9. Moce-Llivina, L. and J. Jofre, A method to maintain mammalian cells for days alive at 4 degrees C. Cytotechnology, 2004. 46(1): p. 57-61.

10. Polge, C., A.U. Smith, and A.S. Parkes, Revival of spermatozoa after vitrification and dehydration at low temperatures. Nature, 1949. 164(4172): p. 666.

11. Sputtek, A., et al., Bioequivalence comparison of a new freezing bag (CryoMACS((R))) with the Cryocyte((R)) freezing bag for cryogenic storage of human hematopoietic progenitor cells. Cytotherapy, 2011. 13(4): p. 481-9.

12. Heidemann, R., et al., A new seed-train expansion method for recombinant mammalian cell lines. Cytotechnology, 2002. 38(1-3): p. 99-108.

13. Heidemann, R., et al., Characterization of cell-banking parameters for the cryopreservation of mammalian cell lines in 100-mL cryobags. Biotechnol Prog, 2010. 26(4): p. 1154-63.

14. Mason, $\mathrm{C}$. and E. Manzotti, Regenerative medicine cell therapies: numbers of units manufactured and patients treated between 1988 and 2010. Regen Med, 2010. 5(3): p. 30713.

15. Mesoblast. Mesoblast Provides Update on Clinical Programs of Prochymal for Crohn's Disease and Acute Graft Versus Host Disease. 2014; Available from: https://globenewswire.com/news-release/2014/04/29/630744/10078747/en/MesoblastProvides-Update-on-Clinical-Programs-of-Prochymal-for-Crohn-s-Disease-and-Acute-GraftVersus-Host-Disease.html.

16. Health Canada. Summary Basis of Decision (SBD) for PROCHYMAL ${ }^{\circledR} .2012$; Available from: http://www.hc-sc.gc.ca/dhp-mps/prodpharma/sbd-smd/drug$\mathrm{med} / \mathrm{sbd}$ smd 2012 prochymal 150026-eng.php.

17. Van Buskirk, R.G., et al., Cryopreservation: It's not just about cell yield. Bioprocess International, 2005. 3(4): p. 64-72.

18. Li, Y., J.C. Tan, and L.S. Li, Comparison of three methods for cryopreservation of human embryonic stem cells. Fertil Steril, 2010. 93(3): p. 999-1005.

19. $\mathrm{Xu}, \mathrm{X}$., et al., The roles of apoptotic pathways in the low recovery rate after cryopreservation of dissociated human embryonic stem cells. Biotechnol Prog, 2010. 26(3): p. 827-37.

20. François, M., et al., Cryopreserved mesenchymal stromal cells display impaired immunosuppressive properties as a result of heat-shock response and impaired interferon- $\gamma$ licensing. Cytotherapy, 2012. 14(2): p. 147-152. 
21. Moll, G., et al., Do Cryopreserved Mesenchymal Stromal Cells Display Impaired Immunomodulatory and Therapeutic Properties? Stem cells (Dayton, Ohio), 2014. 32(9): p. 2430-2442.

22. Luetzkendorf, J., et al., Cryopreservation does not alter main characteristics of Good Manufacturing Process-grade human multipotent mesenchymal stromal cells including immunomodulating potential and lack of malignant transformation. Cytotherapy, 2015. 17(2): p. 186-98.

23. Cruz, F.F., et al., Freshly thawed and continuously cultured human bone marrow-derived mesenchymal stromal cells comparably ameliorate allergic airways inflammation in immunocompetent mice. Stem Cells Transl Med, 2015. 4(6): p. 615-24.

24. Baboo, J., et al., The important relationship between cooling and thawing rates on human $t$ cell quality. Cytotherapy. 19(5): p. S29.

25. Heo, Y.S., et al., "Universal" vitrification of cells by ultra-fast cooling. Technology, 2015. 3(1): p. 64-71.

26. Beier, A.F., J.C. Schulz, and H. Zimmermann, Cryopreservation with a twist - Towards a sterile, serum-free surface-based vitrification of hESCs. Cryobiology, 2013. 66(1): p. 8-16.

27. Hunt, C.J. and P.M. Timmons, Cryopreservation of human embryonic stem cell lines. Methods Mol Biol, 2007. 368: p. 261-70.

28. Li, T., et al., Bulk vitrification of human embryonic stem cells. Hum Reprod, 2008. 23(2): p. 358-64.

29. Fountain, D., et al., Liquid nitrogen freezers: a potential source of microbial contamination of hematopoietic stem cell components. Transfusion, 1997. 37(6): p. 585-91.

30. Bielanski, A. and G. Vajta, Risk of contamination of germplasm during cryopreservation and cryobanking in IVF units. Hum Reprod, 2009. 24(10): p. 2457-67.

31. Massie, I., et al., GMP Cryopreservation of Large Volumes of Cells for Regenerative Medicine: Active Control of the Freezing Process. Tissue Engineering. Part C, Methods, 2014. 20(9): p. 693-702.

32. Parmegiani, L., et al., Sterilization of liquid nitrogen with ultraviolet irradiation for safe vitrification of human oocytes or embryos. Fertil Steril, 2010. 94(4): p. 1525-8.

33. Center for Biologics Evaluation and Research (CBER). Guidance for Industry: Q3C - Tables and Lists, U.S. Food and Drug Administration (FDA). 2012; Available from: https://www.fda.gov/downloads/drugs/guidances/ucm073395.pdf.

34. International Conference on Harmonization (ICH). Impurities: Guideline for Residual Solvents Q3C(R6). ICH Harmonised Tripartite Guideline 2011; Available from: www.ema.europa.eu/docs/en GB/document...guideline/2011/.../WC500104258.pdf.

35. Pomper, G.J., Febrile, Allergic, and Nonimmune Transfusion Reactions, in Rossi's Principles of Transfusion Medicine. 2009, Wiley-Blackwell. p. 826-846.

36. Brobyn, R.D., The human toxicology of dimethyl sulfoxide. Annals of the New York Academy of Sciences, 1975. 243(1): p. 497-506.

37. Sharp, D.M.C., et al., Amphipathic polymer-mediated uptake of trehalose for dimethyl sulfoxide-free human cell cryopreservation()(). Cryobiology, 2013. 67(3): p. 305-311.

38. Hossain, A.M. and C.O. Osuamkpe, Sole use of sucrose in human sperm cryopreservation. Arch Androl, 2007. 53(2): p. 99-103.

39. Eroglu, A., et al., Intracellular trehalose improves the survival of cryopreserved mammalian cells. Nat Biotechnol, 2000. 18(2): p. 163-7.

40. Zhou, X., et al., Loading trehalose into red blood cells by electroporation and its application in freeze-drying. Cryo Letters, 2010. 31(2): p. 147-56.

41. Hess, J.R., Scientific problems in the regulation of red blood cell products. Transfusion, 2012. 52(8): p. 1827-35.

42. Collins, G.M., M. Bravo-Shugarman, and P.I. Terasaki, Kidney preservation for transportation. Initial perfusion and 30 hours' ice storage. Lancet, 1969. 2(7632): p. 1219-22. 
43. Lee, C.Y. and M.J. Mangino, Preservation methods for kidney and liver. Organogenesis, 2009. 5(3): p. 105-112.

44. Ginis, I., B. Grinblat, and M.H. Shirvan, Evaluation of bone marrow-derived mesenchymal stem cells after cryopreservation and hypothermic storage in clinically safe medium. Tissue Eng Part C Methods, 2012. 18(6): p. 453-63.

45. Day, A.G.E., et al., Hypothermic and cryogenic preservation of artificial neural tissue made using differentiated CTX human neural stem cells in collagen gels. European Cells and Materials, 2015. 29(3): p. 44.

46. ClinicalTrials.gov. Intralymphatic eASC Administration in Healthy Volunteers. ClinicalTrials.gov Identifier: NCT01743222 2013; Available from: https://clinicaltrials.gov/ct2/show/NCT01743222.

47. Chen, B., et al., A novel alternative to cryopreservation for the short-term storage of stem cells for use in cell therapy using alginate encapsulation. Tissue Eng Part C Methods, 2013. 19(7): p. 568-76.

48. Swioklo, S., A. Constantinescu, and C.J. Connon, Alginate-Encapsulation for the Improved Hypothermic Preservation of Human Adipose-Derived Stem Cells. Stem Cells Transl Med, 2016. 5(3): p. 339-49.

49. Parsley, W.M. and D. Perez-Meza, Review of Factors Affecting the Growth and Survival of Follicular Grafts. Journal of Cutaneous and Aesthetic Surgery, 2010. 3(2): p. 69-75.

50. Reyes, B.A., J.S. Pendergast, and S. Yamazaki, Mammalian Peripheral Circadian Oscillators Are Temperature Compensated. Journal of biological rhythms, 2008. 23(1): p. 95-98.

51. Plesnila, N., et al., Effect of hypothermia on the volume of rat glial cells. The Journal of Physiology, 2000. 523(Pt 1): p. 155-162.

52. Baust, J.G., D. Gao, and J.M. Baust, Cryopreservation: An emerging paradigm change. Organogenesis, 2009. 5(3): p. 90-96.

53. Baust, J.M., Properties of Cells and Tissues Influencing Preservation Outcome, in Advances in Biopreservation. 2006, CRC Press. p. 63-87. 